\title{
PENGARUH PERSEPSI K3 TERHADAP PERILAKU PEKERJA BAGIAN PRODUKSI PT. BOSOWA BETON INDONESIA MAKASSAR
}

\author{
Stenly Jacob Wenno* \\ Kesehatan Masyarakat, Sekolah Tinggi Ilmu Kesehatan Tamalatea, Makassar, Indonesia \\ H. Jalil Genisa \\ Kesehatan Masyarakat, Sekolah Tinggi Ilmu Kesehatan Tamalatea, Makassar, Indonesia \\ Muhammad Rifai \\ Kesehatan Masyarakat, Sekolah Tinggi Ilmu Kesehatan Tamalatea, Makassar, Indonesia \\ *E-mail korespondensi: stenlyjac97@gmail.com
}

\begin{abstract}
ABSTRAK
Persepsi terhadap Keselamatan dan Kesehatan Kerjaadalahpandanganpekerjaterhadapapa yang di berikan perusahaan yang bertujuan supaya pekerja terjaga dan terjamin keselamatan dan kesehatan kerjanya. Penelitian ini bertujuan untuk menganalisis pengaruh persepsi keselamatan dan kesehatan kerja terhadap perilaku pekerja di bagian produksi beton precast PT. Bosowa Beton Indonesia. Metode penelitian yang digunakan dalam penelitian ini adalah penelitian analitik dengan desain cross sectional study, dengan jumlah sampel sebanyak 40 pekerja. Hasil penelitian menunjukan bahwa untuk variabel yang memengaruhi secara signifikan terhadap perilaku pekerja produksi beton precast PT. Bosowa Beton Indonesia adalah pengetahuan $K 3$ ( $\rho$ value $0,000<\alpha 0,05)$, penggunaan alat pelindung diri ( $\rho$ value $0,000<\alpha$ 0,05), dan ketersediaan sarana dan prasarana K3 ( $\rho$ value 0,016 < $\alpha 0,05)$, sedangkan variabel yang tidak memengaruhi terhadap perilaku pekerja produksi beton precast adalah sistem manajemen $K 3$ ( $\rho$ value $0,545>\alpha 0,05)$ dan risiko bahaya dari penerapan $K 3$ ( $\rho$ value 0,103 $>\alpha$ 0,05). Variabel yang paling dominan memengaruhi persepsi K3 terhadap perilaku pekerja adalah pengetahuan K3 dan penggunaan alat pelindung diri. Kesimpulan penelitian ini adalah ada pengaruh pengetahuan $K 3$, penggunaan alat pelindung diri, dan ketersediaan sarana prasarana $K 3$ terhadap perilaku pekerja bagian produksi beton precast PT. Bosowa Beton Indonesia.
\end{abstract}

Kata Kunci : Persepsi K3, Pengetahuan, APD, dan Perilaku Pekerja

\begin{abstract}
Perceptions of Occupational Safety and Health are employee views of what is given company that aims to keep employees safe and secure at work. This study aims to analyze the that influence the perception of occupational safety and health on the behavior of workers in theconcrete production section of precast PT Bosowa Beton Indonesia.The research method used in this research is analytical research with a cross sectional study design, with a sample of 40 workers. The results showed that the variables that significantly influenced the behavior of workers in the production ofconcrete at precast PT Bosowa Beton Indonesia were K3 Knowledge ( $\rho$ value $0.000<0.05)$, Application of K3 personal protective equipment $(\rho$ value $0.000<0.05)$, and Availability of $K 3$ facilities and infrastructure $(\rho$ value $0.016<0.05$, while the variables that do not affect the behavior ofconcrete production workers precast are the K3 management system ( $\rho$ value $0.545>0.05$ ), and the risk of harm from the application of K3 ( value $0.103>0.05$, The most dominant variables that influence the perception of K3 on worker
\end{abstract}


behavior are knowledge and personal protective equipment. Conclusion of this study is that there is an influence on K3 knowledge, K3 personal protective equipment, and Availability of $K 3$ infrastructure on behavior workers in the production ofconcrete precast PT Bosowa Beton Indonesia.

Keywords: Perception of K3, Knowledge, PPE, and Worker Behavior

\section{PENDAHULUAN}

Keselamatan dan Kesehatan Kerja (K3) merupakan suatu upaya perlindungan kerja agar tenaga kerja selalu dalam keadaan selamat dan sehat selama melakukan pekerjaan ditempat kerja, serta sumber dan proses produksi dapat digunakan secara aman dan efisien. Tenaga kerja merupakan faktor yang sangat menentukan bagi perusahaan, tenaga kerja juga merupakan faktor produksi yang memiliki peran penting dalam kegiatan perusahaan.

Perlindungan tenaga kerja memiliki beberapa aspek dan salah satunyayaitu perlindungan keselamatan, perlindungan tersebut bermaksud agar tenagakerja secara aman melakukan kerjanya sehari-hari untuk meningkatkan produktivitas. Karyawan dalam melaksanakan pekerjaan ini akan menghadapi ancaman bagi keselamatan dan kesehatannya yang akan datang dari pelaksanaan tugas mereka tersebut. Karena itu dalam rangka menjalankan usaha yang aman maka program perlindungan bagi karyawan melalui penerapan Sistem Manajemen Keselamatan dan Kesehatan Kerja (SMK3) harus dilakukan secara konsisten. Hal ini sesuai dengan UndangUndang Nomor, 1 Tahun 1970, tentang Keselamatan Kerja dan Undang-Undang No. 13 Tahun 2003, tentang Ketenagakerjaan, yang menyatakan kewajiban pengusaha melindungi tenaga kerja dari potensi bahaya yang dihadapinya (Shiddiq et al., 2014). Keselamatan dan Kesehatan Kerja (K3) sangat berpengaruh di tempat kerja agar pekerja dapat bekerja secara aman dan sehat, untuk itu pengetahuan dan pemahaman mengenai Keselamatan dan Kesehatan Kerja (K3) harus diterapkan dan diberikan kepada setiap pekerja agar pekerja memiliki persepsi yang baik tentang keselamatan dan kesehatan kerja (K3).

Sebagai perusahaan khususnya pada bagian produksi yang banyak berhubungan dengan alat-alat yang berbahaya. Alat-alat berbahaya tersebut berpotensi dalam mengakibatkan kecelakaan di tempat kerja, apabila pekerja memiliki persepsi buruk terhadap keselamatan dan kesehatan kerja (K3), serta apabila pekerja tidak berhati-hati dalam melakukan pekerjaannya. Persepsi terhadap Keselamatan dan Kesehatan Kerja adalah pandangan karyawanterhadapapa yang diberikanperusahaan yang bertujuan agar karyawan terjaga dan terjamin keselamatan dan kesehatan kerjanya, ada beberapa faktor yang yang dianggap kurang penting bagi karyawan dalam bekerja salah satunya adalah penggunaan alat pelindung diri saat bekerja. Hal tersebut dapat menimbulkan risiko kecelakaan kerja oleh karena itu aspek keselamatan perlu diupayakan agar pekerja dapat bekerja secara aman, nyaman, dan selamat. Untuk itu diperlukan observasi dari perusahaan atau juga dari peneliti untuk mengetahui faktor-faktor yang mempengaruhi persepsi keselamatan dan kesehatan kerja terhadap perilaku pekerja.

Terkait pada perilaku pekerja, maka penulis mengambil obyek penelitian pada PT Bosowa Beton Indonesia, yang bertempat di Jalan Insinyur Sutami Terowongan, Lorong 2, Bira, Toll, Kota Makassar, Sulawesi Selatan. Dari data awal yang diperoleh dari PT Bosowa Beton Indonesia tercatat sebanyak 40 orang yang aktif bekerja pada produksi beton (precast), yang akan dijadikan sampel untuk mengetahui faktor-faktor yang mempengaruhi persepsi keselamatan dan kesehatan kerja, dilihat dari beberapa faktor terkait Pengetahuan, sistem manajemen keselamatan dan kesehatan kerja (SMK3), Alat Pelindung Diri (APD), sarana dan prasarana, serta risiko bahaya, yang secara langsung atau tidak langsung memberikan dampak yang baik bagi perusahaan (PT Bosowa Beton Indonesia).

Berdasarkan uraian masalah yang telah diuraikan di atas, maka peneliti tertarik untuk melakukan penelitian tentang Pengaruh Persepsi Keselamatan dan Kesehatan Kerja (K3) Terhadap Perilaku Pekerja pada Bagian Produksi Beton Precast di PT. Bosowa Beton Indonesia Makassar. 


\section{BAHAN DAN METODE}

Penelitian ini merupakan penelitian kuantitatif.Metode penelitian kuantitatif dapat diartikan sebagai metode penelitian yang berlandaskan pada filsafat positivisme, digunakan untuk meneliti pada populasi atau sampel tertentu. Pendekatan penelitian yang digunakan adalah penelitian asosiatif yaitu penelitian yang digunakan untuk menghubungkan variabel independen dan variabel dependen. Desain penelitian yang digunakan adalah cross sectional study (Sugiyono, 2017). Penelitian ini dilakukan di PT Bosowa Beton Indonesia dengan waktu penelitian bulan April-Mei 2021. Dalam penelitian ini populasi dan sampel diambil secara total sampling, dengan jumlah sampel seluruhnya berjumlah 40 pekerja.

\section{HASIL DAN PEMBAHASAN}

PT Bosowa Beton Indonesia adalah salah satu suplayerready mix terbesar yang ada di Sulawesi selatan dan juga sebagai produsen hasil olahan beton jadi (precast). Terletak di jl. Ir Sutami (Samping Terowongan 2 Tol) Kecamatan Tamanlarea Kota Makassar. Penelitian ini dilakukan di batching plant yang ada di Kima Makassar, dengan jumlah karyawan adalah 40 orang bagian produksi precast. Adapun hasil penelitian ini disajikan dalam bentuk tabel disertai dengan narasi, mulai dari analisis univariat hingga bivariat.

Tabel 1. Menunjukan bahwa kelompok umur responden tertinggi pada kelompok umur 3039 tahun sebanyak 18 (45,0\%), sedangkan terendah kelompok umur 40-49 tahun sebanyak 7 $(17,5)$. Berdasarkan pendidikan terakhir responden, yang tertinggi pada Tamatan SMA sebanyak $26(65,5 \%)$ dan terendah pada Tamatan DIII sebanyak $1(2,5 \%)$. Berdasarkan jenis kelamin, semua responden dalam penelitian ini semua berjenis kelamin laki-laki.

Tabel 1. Distribusi frekuensi karakteristik responden.

\begin{tabular}{|c|c|c|}
\hline Karaketristik Responden & Jumlah & Persen \\
\hline \multicolumn{3}{|l|}{ Kelompok Umur } \\
\hline $20-29$ & 15 & 37,5 \\
\hline $30-39$ & 18 & 45,0 \\
\hline $40-49$ & 7 & 17,5 \\
\hline \multicolumn{3}{|l|}{ Pendidikan Terakhir } \\
\hline SMP & 3 & 7,5 \\
\hline SMA & 26 & 65,5 \\
\hline DIII & 1 & 2,5 \\
\hline S-1 & 10 & 25,5 \\
\hline \multicolumn{3}{|l|}{ Jenis Kelamin } \\
\hline Laki-Laki & 40 & 100,0 \\
\hline
\end{tabular}

Tabel 2 menunjukkan bahwa hasil analisis variabel pengetahuan tentang K3 dalam penelitian ini menunjukkan bahwa pengetahuan cukup pekerja mengenai $\mathrm{K} 3$ dengan perilaku pekerja baik sebesar 96,8\%, sedangkan pengetahuan cukup pekerja mengenai K3 dengan perilaku pekerjakurang sebesar $11,1 \%$. Hasil uji statistik diperoleh nilai $\rho$ value $0,000<0,05$, sehingga Ha diterima. Hal tersebut berarti ada pengaruh pengetahuan keselamatan dan kesehatan kerja terhadap perilaku pekerja.

Di samping itu, Tabel 2 menunjukkan bahwa hasil analisis variabel sistem manajemen, pekerja yang paham tentang SMK3 dengan perilaku baik sebesar 93,5\%, sedangkan pekerja yang paham tentang SMK3 dengan perilaku kurang sebesar 8,3\%. H Hasil uji statistik diperoleh nilai $\rho$ value $0,545>0,05$, sehingga Ha ditolak. Hal tersebut berarti tidak ada pengaruh sistem manajemen keselamatan dan kesehatan kerja terhadap perilaku pekerja.

Selain itu, Tabel 2 menunjukkan hasil analisis variabel kepatuhan penggunaan APD dalam penelitian ini yaitu pekerja yang patuh menggunakan APD dengan perilaku pekerja baik yaitu sebesar $100,0 \%$, sedangkan pekerja yang patuh dalam menggunakan APD dengan perilaku pekerja kurang yaitu sebesar $11,1 \%$. Hasil uji statistik diperoleh nilai $\rho$ value $0,000<0,05$, sehingga Ha diterima. Hal tersebut berarti ada pengaruh APD terhadap perilaku pekerja. 
Tabel 2. Hubungan variabel independen dan variabel dependen

\begin{tabular}{|c|c|c|c|c|c|c|c|c|}
\hline \multirow{3}{*}{ Variabel } & & \multicolumn{4}{|c|}{ Perilaku Pekerja } & \multirow{2}{*}{\multicolumn{2}{|c|}{ Jumlah }} & \multirow{3}{*}{ P_Value } \\
\hline & & \multicolumn{2}{|r|}{ Baik } & & \multirow{2}{*}{$\frac{\text { Kurang }}{\%}$} & & & \\
\hline & & $\mathrm{f}$ & $\%$ & $\mathrm{f}$ & & $\mathrm{f}$ & $\%$ & \\
\hline \multicolumn{9}{|l|}{ Pengetahuan } \\
\hline \multirow{3}{*}{$\begin{array}{l}\text { cukup } \\
\text { Kurang }\end{array}$} & & 30 & 96,8 & 1 & 11,1 & 31 & 77,5 & \multirow{3}{*}{0,000} \\
\hline & & 1 & 3,2 & 8 & 88,9 & 9 & 22,5 & \\
\hline & Jumlah & 31 & 100,0 & 9 & 100,0 & 40 & 100,0 & \\
\hline \multicolumn{9}{|c|}{ Sistem Manajemen K3 } \\
\hline Paham & & 29 & 93,5 & 8 & 8,3 & 37 & 92,5 & \multirow{3}{*}{0,545} \\
\hline Tidak Paham & & 2 & 6,5 & 1 & 11,1 & 3 & 7,5 & \\
\hline & Jumlah & 31 & 100,0 & 9 & 100,0 & 40 & 100,0 & \\
\hline \multicolumn{9}{|l|}{ Alat Pelindung Diri } \\
\hline Patuh & & 31 & 100,0 & 1 & 11,1 & 32 & 80,0 & \multirow{3}{*}{0,000} \\
\hline Tidak Patuh & & 0 & 0,0 & 8 & 88,9 & 8 & 20,0 & \\
\hline & Jumlah & 31 & 100,0 & 9 & 100,0 & 40 & 100,0 & \\
\hline \multicolumn{9}{|c|}{ Sarana dan Prasarana } \\
\hline Tersedia & & 29 & 93,5 & 5 & 55,6 & 34 & 85,0 & \multirow{3}{*}{0,016} \\
\hline Tidak Tersedia & & 2 & 6,5 & 4 & 44,4 & 6 & 15,0 & \\
\hline & Jumlah & 31 & 100,0 & 9 & 100,0 & 40 & 100,0 & \\
\hline \multicolumn{9}{|l|}{ Risiko Bahaya } \\
\hline Tidak Berisiko & & 23 & 74,2 & 4 & 44,4 & 27 & 67,5 & \multirow{3}{*}{0,103} \\
\hline \multirow[t]{2}{*}{ Berisiko } & & 8 & 25,8 & 5 & 55,6 & 13 & 32,5 & \\
\hline & Jumlah & 31 & 100,0 & 9 & 100,0 & 40 & 100,0 & \\
\hline
\end{tabular}

Berdasarkan variabel sarana dan prasarana menunjukan bahwa hasil analisis variabel sarana dan prasarana, pekerja yang mengaku bahwa sarana dan prasarana tersedia dengan perilaku pekerja baik yaitu sebesar $93,5 \%$, sedangkan sarana dan prasarana tersedia dengan perilaku pekerja kurang sebesar 55,6\%. Hasil uji statistik diperoleh nilai $\rho$ value $0,016<0,05$, sehingga Ha diterima. Hal tersebut berarti ada pengaruh pemakaian sarana dan prasarana terhadap perilaku pekerja

Variabel risiko bahaya menunjukanbahwa hasil analisis variabel Risiko Bahaya dalam penelitian ini yaitu pekerja yang merasa tidak berisiko dengan perilaku pekerja baik yaitu sebesar $74,2 \%$, sedangkan pekerja yang tidak merasa berisiko saat menjalankan pekerjaannya dengan perilaku pekerja kurang sebesar 44,4\%. Hasil uji statistik diperoleh nilai $\rho$ value $0,103>$ 0,05 , sehingga Ha ditolak. Hal tersebut berarti tidak ada pengaruh risiko bahaya terhadap perilaku pekerja. Pengujian hasil statistik Tabel 2 menggunakan Fisher's Exact Test untuk mengetahui hubungan antara variabel independen dan variabel dependen. Dari kelima variabel diatas dapat dijelaskan secara rinci sebagai berikut.

\section{1) Pengetahuan}

Keselamatan dan Kesehatan Kerja merupakan suatu usaha dan upaya untuk menciptakan perlindungan dan keamanan dari risiko kecelakaan dan bahaya baik fisik, mental maupun emosional terhadap pekerja, perusahaan, masyarakat dan lingkungan (Sucipto, 2014). Pengetahuan tentang K3 menjadi sangat penting untuk diketahui para pekerja terutama pada industri-industri atau perusahaan-perusahaan dengan risiko kerja yang cukup tinggi. PT bosowa Beton Indonesia merupakan salah satu perusahaan yang memiliki risiko kerja yang cukup tinggi sehingga semua pekerja diharapkan memiliki pengetahuan tentang K3 yang cukup. Hasil penelitian menunjukkan bahwa pengetahuan pekerja dibagian produksi PT Bosowa Beton Indonesia cukup baik yaitu sebesar 77,5\%, hal tersebut menunjukkan bahwa sekitar 22,5\% pekerja ada yang memiliki pengetahuan K3 kurang baik, hal ini yang harus menjadi kekhawatiran terhadap hal-hal yang tidak diinginkan. 
Bedasarkan hasil uji statistik diperolah nilai $\rho$ value $0,000<0,05$, sehingga Ha diterima. Hal tersebut berarti ada pengaruh pengetahuan keselamatan dan kesehatan kerja terhadap perilaku pekerja di bagian produksi beton PT Bosowa Beton Indonesia. Hal ini menunjukkan bahwa pengetahuan kurang akan memengaruhi terhadap perilaku pekerja yang kurang baik, sehingga hal ini dapat memberikan dampak buruk untuk perusahaan terkhusus untuk pekerja itu sendiri. Penelitian ini sejalan dengan penelitian yang dilakukan oleh Suartana et al. (2021) menunjukkan bahwa pengetahuan K3 yang mempunyai korelasi yang baik terhadap perilaku pekerja (Y1) yakni variabelalat pelindung diri (X3) dan resiko K3 (X5). Dengan demikian pengetahuan K3 mempunyai hubungan (korelasi) yang kuat dan pengaruh yang signifikan terhadap perilaku pekerja.Sehingga sangat diharapkan baik pihak perusahaan maupun pihak pekerja untuk meningkatkan pengetahuan dan pemahaman terhadap keselamatan dan kesehatan kerja, sehingga dapat bekerja dengan baik dan produktif.

\section{2) Sistem Manajemen K3 (SMK3)}

SMK3 (Sistem Manajemen Keselamatan dan Kesehatan Kerja) merupakan bagian dari sistem manajemen perusahaan secara keseluruhan dalam rangka pengendalian risiko yang berkaitan dengan kegiatan kerja guna terciptanya tempat kerja yang efisien, aman dan produktif. Hal tersebut sesuai dengan Peraturan Pemerintah No.50/2012 (Pangkey, 2012). SMK3 diwajibkan bagi perusahaan yang mempekerjakan lebih dari 100 orang dan mempunyai tingkat potensi bahaya tinggi. Untuk itu perusahaan diwajibkan menyusun rencana $\mathrm{K} 3$, dalam menyusun rencana K3 tersebut, pengusaha melibatkan Ahli K3, Panitia Pembina Keselamatan dan Kesehatan Kerja (P2K3), Wakil Pekerja dan Pihak Lain yang terkait. Penerapan Sistem Manajemen Keselamatan dan Kesehatan Kerja (SMK3) berdasarkan Peraturan Pemerintah RI No. 50 Tahun 2012 yaitu Penetapan kebijakan K3, perencanaan K3, pelaksanaan rencana K3, pemantauan dan evaluasi kinerja K3 dan peninjauan dan peningkatan kinerja SMK3 (Susanti et al., 2019). SMK3 merupakan hal penting untuk dipahami, bukan hanya pihak perusahaan itu sendiri namun juga para pekerja, pekerja diharapkan memahami dengan baik tentang SMK3.Hasil penelitian ini menunjukkan bahwa pekerja sudahmemahamitentang SMK3.

Bedasarkan hasil uji statistik diperoleh nilai $\rho$ value $0,545>0,05$, sehingga Ha ditolak. Hal tersebut berarti tidak pengaruh sistem manajemen keselamatan dan kesehatan kerja terhadap perilaku pekerja di bagian produksi beton PT Bosowa Beton Indonesia. Hal tersebut memberikan asumsi bahwa semua pekerja sudah memiliki pemahaman yang baik dengan perilaku pekerja yang cukup baik. Meskipun demikian baik perusahaan maupun pekerja harus tetap berusaha mempertahankan hal tersebut sehingga dapat tetap meningkatkan produktivitas perusahaan. Sebuah penelitian yang dilakukan (Susanti et al., 2019) menunjukkan bahwa manajemen tidak berpengaruh terhadap kinerja, maka dapat dikatakan manajemen hanya mempengaruhi perilaku dan tidak mempengaruhi kinerja. Maka dari itu sangat penting untuk meningkatkan pehamanan secara keseluruhan kepada semua pekerja sehingga kinerja tetap baik dan terhindar dari kecelakaan kerja yang dapat merugikan pihak perusahaan terkhusus pihak pekerja.

\section{3) Alat Pelindung Diri (APD)}

Alat Pelindung Diri (APD) merupakan seperangkat alat yang digunakan oleh tenaga kerja untuk melindungi seluruh atau sebagian tubuhnya terhadap kemungkinan adanya potensi bahaya kecelakaan kerja pada tempat kerja. Penggunaan alat pelindung diri sering dianggap tidak penting ataupun remeh oleh para pekerja, terutama pada pekerja yang bekerja pada sektor informal. Padahal penggunaan alat pelindung diri ini sangat penting dan berpengaruh terhadap keselamatan dan kesehatan pekerja. Kedisiplinan para pekerja dalam menggunakan alat pelindung diri tergolong masih rendah sehingga resiko terjadinya kecelakaan kerja yang dapat membahayakan pekerja cukup besar (Noviandry, 2013).

Alat Pelindung Diri (APD) merupakan salah satu hal penting yang harus selalu disediakan dan digunakan dengan baik dan benar. Kesalahan dalam penggunaan atau bahkan tidak menggunakan sama sekali dapat memberikan dampak besar bagi pekerja. Sehingga kepatuhan 
dalam penggunaan APD merupakan hal yang sangat-sangat perluuntuk diperhatikan.Hal ini sangat berkaitan dengan perilaku pekerja saat menjalankan pekerjaannya.Pada hasil penelitian menunjukkan bahwa kepatuhan pekerja dalam penggunaan APD lebih besar dibandingkan pekerja yang tidak patuh dalam menggunakan APD, hal ini menunjukkan bahwa kesadaran penggunaan APD sudah cukup baik. Hasil uji statistik diperoleh nilai $\rho$ value $0,000<0,05$, sehingga Ha diterima. Hal tersebut berarti ada pengaruh penggunaan APD terhadap perilaku pekerja di bagian produksi beton PT Bosowa Beton Indonesia. Hal ini memberikan asumsi bahwa pekerja memiliki perilaku yang kurang baik, dan tidak patuh menggunakan APD, sehingga perlu menjadi perhatian dan pengawasan yang lebih ketat lagi.

Sebuah penelitian yang dilakukan di sebuah rumah sakit menunjukkan bahwa terdapat pengaruh yang signifikan pengawasan perawat dan ketersediaan APD terhadap kepatuhan penggunaan APD di IBS RSUD Ulin Banjarmasin. Oleh karena itu pengawasan dan ketersediaan APD di IBS RSUD Ulin perlu dipertahankan dan ditingkatkan lagi sehingga kepatuhan penggunaan APD ini dapat menjadi budaya dalam bekerja (Sudarmo et al., 2017). Selain itu pengetahuan tentang alat pelindung diri juga menjadi hal yang sangat penting, karena hal ini dapat berpengaruh terhadap perilaku pekerja terhadap penggunaan APD, sebuah penelitian memperoleh hasil bahwa secara persial variabel pengetahuan tentang alat pelindung diri berpengaruh positif dan signifikan terhadap kepatuhan penggunaan alat pelindung diri (Jatmiko, 2019). Hasil sebuah penelitian menunjukkan bahwa ada hubungan antara pelatihan dengan penggunaan APD, ada hubungan antara sikap penggunaan APD, ada hubungan antara pengawasan dengan penggunaan APD, ada hubungan antara hukuman dengan penggunaan APD, dan ada hubungan antara penghargaan penggunaan APD (Noviandry, 2013). Sehingga diharapkan pihak terkait memberikan pelatihan terkait APD sehinga pekerja lebih paham dalam menggunakan dan manfaat APD, memberikan apresiasi kepada pekerja yang patuh dalam menggunakan APD, pengawasan dan pemberian hukuman dapat dilakukan demi keselamatan dan kesehatan pekerja.

\section{4) Sarana dan Prasarana}

Sarana Prasarana mencakup nilai-nilai yang mempunyai makna yang sama bagi para anggotanya, keyakinan yang sama tentang keberadaan organisasi dan perilaku tertentu yang diharapkan ditampilkan oleh semua anggota organisasi (Siagian, 2013). Terpenuhinya sarana dan prasarana dalan menjalankan pekerjaan menjadi salah satu faktor penunjang dalan keberhasilan atau meningkatnya kinerja dan produktifitas pekerja.Hasil penelitian ini menunjukkan bahwa sebagian besar pekerja berasumsi bahwa sarana dan prasarana dibagian produksi PT Bosowa Beton Indonesia sudah tersedia.Hal ini seharusnya menjadi sebuah hal baik bagi perusahaan dalam meningkatkan kinerja dan produktivitas perusahaan.

Hasil uji statistik diperoleh nilai $\rho$ value $0,016<0,05$, sehingga Ha diterima. Hal tersebut berarti ada pengaruh sarana dan prasarana terhadap perilaku pekerja di bagian produksi beton PT Bosowa Beton Indonesia. Hal ini memberikan gambaran bahwa ternyata pekerja yang berasumsi sarana dan prasarana tidak tersedia dengan baik memiliki perilaku kerja yang kurang. Sebuah hasil penelitian menunjukkan bahwa Sarana Prasarana, Kompetensi Kerja dan Iklim Organisasi terbukti memiliki pengaruh positif dan signifikan terhadap perilaku dan Kinerja (Yulihardi \& Akmal, 2019). Sangat diharapkan agar pihak manajemen selalu memperhatikan sarana dan prasarana dan lebih fokus untuk memperbaiki dan mengevaluasi indikatorindikatornya sehingga dapat dirasakan untuk semua pekerja.

\section{5) Risiko Bahaya}

Risiko K3 adalah perpaduan antara peluang dan frekuensi terjadinya peristiwa K3 dengan akibat yang ditimbulkannya dalam kegiatan konstruksi. Sedangkan bahaya adalah segala kondisi yang dapat merugikan baik cidera atau kerugian lainnya, atau Bahaya adalah sumber, situasi atau tindakan yang berpotensi menciderai manusia atau sakit penyakit atau kombinasi dari semuanya (Nurdin, 2014). Sehingga risiko bahaya adalah peluang dan frekuensi yang dapat terjadi dalam kegiatan kontruksi yang berpotensi mencederai manusia atau menyebabkan 
penyakit atau bahkan menderita penyakit dan cedera fisik. Sebuah perusahaan harus selalu mengitung besar risiko kerja dalam perusahaannya bagi semua pekerja yang terlibat. Menurut (Puspitasari, 2010) sebuah perusahaan dapat mengendalikan dan mecegah risiko besar terjadi jika Sistem Manajemen Keselamatan dan Kesehatan Kerja (SMK3) dalam perusahaan telah menerapkan Identifikasi bahaya dan Risiko bahaya sebagai upaya awal pengendalian dan pencegahan kecelakaan kerja .

Hasil penelitian ini menunjukkan bahwa pekerja yang beruasumsi bahwa pekerjaan mereka tidak berisiko lebih besar dibandingkan pekerja yang berasumsi bahwa pekerjaan mereka berisiko. Hasil uji statistik diperoleh nilai $\rho$ value $0,103>0,05$, sehingga Ha ditolak. Hal tersebut berarti tidak ada pengaruh risiko bahaya terhadap perilaku pekerja di bagaian produksi beton PT Bosowa Beton Indonesia. Hal ini memberikan asumsi bahwa risiko pekerjaan baik yang berbahaya maupun tidak berbahaya, tidak memberikan pengaruh apapun terhadap perilaku pekerja. Namun demikan tetap harus memperhatikan keselamatan pekerja dengan mengendalikan risiko kecelakaan kerja saat menjalankan pekerjaan.

Sebuah penelitian yang dilakukan oleh Khamid et al. (2019), cara mengendalikan risiko kerja adalah sebagai dengan memperhatikan faktor-faktor Keselamatan pada Waktu Perencanaan dan Pembangunan Sistem Keamanan (Safety Induction), merancang Perlengkapan dan Pertimbangan Keselamatan Kerja dan Menyediakan Pakaian Pengamana (Penggunaan Alat Pelindung Diri (APD), melakukan Pengawasan yang teratur dan Mengecek serta Mengambil Tindakan untuk Menghilangkan Risiko (Toolbox Meeting), menyelidiki kejadian-kejadian yang mengakibatkan kerusakan dan mengambil Inisiatif untuk melakukan Tindakan Koreksi (Safety Alert), mengembangkan Organisasi Keselamatan dan Kesehatan Kerja (K3) yang Efektif .

Berdasarkan hasil penelitian menunjukkan bahwa pengetahuan $\mathrm{K} 3$ dan penggunaan APD merupakan variabel yang paling besar pengaruhnya terhadap perilaku pekerja, sehingga sebaiknya perusahaan lebih fokus pada kedua hal tersebut namun tidak melupakan hal-hal lain seperti sarana dan prasarana dalam memperbaiki perilaku pekerja dibagian produksi PT Bosowa Beton Indonesia.

\section{KESIMPULAN}

Ada pengaruh pengetahuan keselamatan dan kesehatan kerja terhadap perilaku pekerja di bagian produksi beton precast PT Bosowa Beton Indonesia. Hal ini menunjukan bahwa semakin baik pengetahuan pekerja tentang $\mathrm{K} 3$, maka perilaku pekerja akan baik pula.

Tidak ada pengaruh sistem manajemen keselamatan dan kesehatan kerja terhadap perilaku pekerja di bagian produksi beton precast PT Bosowa Beton Indonesia. Hal ini menunjukan bahwa, pemahaman pekerja yang kurang baik, tentang sistem manajemen K3, tetapi menunjukan perilaku pekerja yang baik.

Ada pengaruh penggunaan pemakaian alat pelindung diri keselamatan dan kesehatan kerja terhadap perilaku pekerja di bagaian produksi beton precast pada PT Bosowa Beton Indonesia. Hal ini menunjukan bahwa pekerja yang patuh dalam menggunakan alat pelindung diri memiliki perilaku yang baik

Ada pengaruh ketersediaan sarana dan prasarana keselamatan dan kesehatan kerja terhadap perilaku pekerja di bagian produksi beton precast PT Bosowa Beton Indonesia. Hal ini menunjukan bahwa ketersediaan sarana dan prasarana menyebabkan perilaku pekerja semakin baik

Tidak ada pengaruh risiko bahaya dari penerapan program keselamatan dan kesehatan kerja terhadap perilaku pekerja dibagian produksi beton precast PT Bosowa Beton Indonesia. Hal ini menunjukan bahwa risiko pekerja yang tidak berisiko menyebabkanperlaku yang baik.

Variabel pengetahuan K3 dan penggunaan APD merupakan variabel yang paling besar pengaruhnya terhadap perilaku pekerja di bagian produksi beton precast PT Bosowa Beton Indonesia. Hal ini menunjukkan bahwa pengetahuan K3 dan penggunaan APD menjadi faktor penting yang dapat memengaruhi perilaku pekerja semakin baik saat bekerja. 


\section{UCAPAN TERIMA KASIH}

Penyusunan artikel ini juga penulis tidak terlepas dari berbagai hambatan dan kesulitan, namun berkat bantuan, bimbingan, serta kerjasama dari berbagai pihak menjadikan semua rintangan tersebut dapat teratasi. Melalui kesempatan ini penulis menyampaikan terima kasih dan penghargaan yang tak terhingga kepada Prof. Dr. Ir. H. Jalil Genisa, M.S dan Dr. Muhammad Rifai, M.Pd, sebagai pembimbing satu dan pembimbing dua, atas semua arahan, perhatian dan bimbingan dengan penuh ketulusan dan kesabaran yang telah dicurahkan kepada penulis.

\section{DAFTAR PUSTAKA}

Jatmiko (2019). Pengaruh Pengetahuan Tentang Pengethauan Alat Pelindung Diri (APD) Terhadap Kepatuhan Penggunaanya Oleh Karyawan Produksi Beta Lactam 2 Di Pt. X Effect of Knowledge About Personal Protective Equipment ( Ppe ) on Compliance With the Use of Beta Lactam 2. Akademi Farmasi Yayasan Putera Indonesia Malang.

Khamid, A., Mulyadi, Y. \& Mukhtasor, M. (2019). Analisa Risiko Keselamatan dan Kesehatan Kerja (K3) terhadap Kecelakaan Kerja serta Lingkungan dengan Menggunakan Metode Hazard and Operability Study (HAZOP) pada Proses Scrapping Kapal, Jurnal Teknik ITS, 7(2), pp. 3-8. doi: 10.12962/j23373539.v7i2.33216.

Noviandry, I. (2013). Faktor-Faktor yang Berhubungan Dengan Perilaku Pekerja Dalam Penggunaan Alat Pelindung Diri (APD) pada Industri Pengelasan Informal di Kelurahan Gondrong, Kecamatan Cipondoh, Kota Tangerang Tahun 2013, UIN Jakarta. Available

at http://repository.uinjkt.ac.id/dspace/bitstream/123456789/24269/1/Ilham Noviandryfkik.pdf.

Nurdin, L. (2014). Identifikasi Bahaya, Penilaian Risiko dan Pengendalian Risiko, The Indonesian Jurnal of Occupational Safety and Health, 3(1), pp. 107-116.

Pangkey, F. (2012). Penerapan Sistem Manajemen Keselamatan dan Kesehatan Kerja (SMK3) Pada Proyek Konstruksi di Indonesia (Studi Kasus: Pembangunan Jembatan Dr. Ir. Soekarno-Manado)', Jurnal Ilmiah MEDIA ENGINEERING, 2(2), pp. 100-113.

Puspitasari, N. (2010). Hazard Identifikasi dan Risk Assesment dalam Upaya Mengurangi Tingkat Risiko di Bagian Produksi PT. Bina Guna Kimia Ungaran, Semarang, Hiperkes dan Keselamatan Kerja, p. 67.

Shiddiq, S., Wahyu, A., \& Muis, M. (2014). Hubungan Persepsi K3 Karyawan dengan Perilaku Tidak Aman di Bagian Produksi Unit IV PT. Semen Tonasa. Media Kesehatan Masyarakat Indonesia, 10(2), 110-116. Retrieved from https://journal.unhas.ac.id/index.php/mkmi/article/view/501

Siagian, S. (2013). Manajemen Sumber Daya Manusia. Jakarta: PT.Bumi Aksara.

Suartana, P., Mandagi, R. J. M. \& Wilar, D. (2021). Pengaruh Pengetahuan Keselamatan dan Kesehatan Kerja (K3) Terhadap Perilaku Pekerja dan Kecelakaan Kerja Pada Proyek di DS LNG Kabupaten Banggai Propinsi Sulawesi Tengah, REKONSTRUKSI TADULAKO: Civil Engineering Journal on Research and Development, pp. 15-22. doi: 10.22487/renstra.v2i1.234.

Sucipto, C. (2014). Keselamatan dan Kesehatan Kerja. Tanggerang: Gosyen Publishing Tarwaka.

Sudarmo, S., Helmi, Z. N. \& Marlinae, L. (2017). Faktor Yang Mempengaruhi Perilaku Terhadap Kepatuhan Penggunaan Alat Pelindung Diri (APD) Untuk Pencegahan Penyakit Akibat Kerja, Jurnal Berkala Kesehatan, 1(2), p. $88 . \quad$ doi: 10.20527/jbk.v1i2.3155.

Sugiyono, 2017. Metode Penelitian Kuantitatif Kualitatif dan R\&D. Bandung: ALFABETA

Susanti, E., Sugianto, W., Sabillah, A., \& Wibowo, S. (2019). Analisa Pengaruh Manajemen Resiko dan Perilaku Kerja Aman Terhadap Kinerja Pekerja Shipyard Kota Batam. Prosiding Seminar Nasional Ilmu Sosial Dan Teknologi (SNISTEK), (2), 79-84. Available at: http://113.212.163.133/index.php/prosiding/article/view/1510. 
Yulihardi, Y. \& Akmal, A. (2019). Ketersediaan Sarana Prasarana, Kompetensi Kerja Dan Iklim Organisasi Dalam Mempengaruhi Perilaku Perawat Di Rumah Sakit Jiwa (RSJ) Puti Bungsu Padang, Eko dan Bisnis: Riau Economic and Business Review, 10(4), pp. 481492. doi: 10.36975/jeb.v10i4.249. 